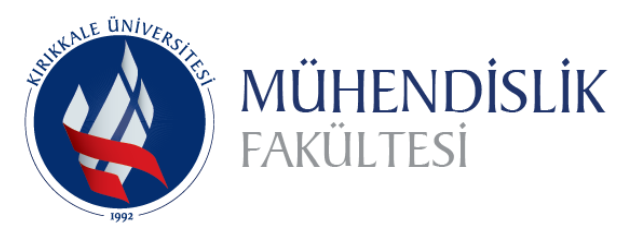
Uluslararası Mühendislik
Araştırma ve Geliştirme Dergisi
UMAGD, (2022) 14(1), 1-9.
International Journal of
Engineering Research and
Development

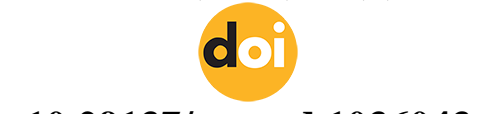
10.29137/umagd.1036043

Cilt/Volume:14 Sayı/Issue:1 Ocak/January 2022

Araştırma Makalesi / Research Article

\title{
21NiCrMo2 Çeliğinin Korozyon Hızına Borlama İşleminin Etkileri
}

\section{Effects of Boronizing on Corrosion Rate of 21NiCrMo2 Steel}

\author{
Salih Ŭgur Bayça1 ${ }^{1}$, Hamza Efe ${ }^{1}$ iD \\ ${ }^{1}$ Kırıkkale Üniversitesi, Mühendislik ve Mimarlık Fakültesi, Metalürji ve Malzeme Mühendisliği Bölümü, 71450 Yahşihan, Kırıkale, TÜRKİYE.
}

Başvuru/Received: 13/12/2021 Kabul/Accepted: 25/12/2021 Çevrimiçi Basım/Published Online: 31/01/2022

Son Versiyon/Final Version: 31/01/2022

$\ddot{\mathbf{O} z}$

Borlama, bir metal yüzeyini seramik tabaka ile kaplama işlemidir. Borlama işlemi sonucunda, metalin bütün yüzeyi ince bir seramik metal-borür tabakası ile kaplanmaktadır. Bu çalışmanın amacı, katı borlama yöntemi ile $21 \mathrm{NiCrMo} 2$ çeliğinin korozyon dayanımı artırmaktır. Bu çalışmada, $21 \mathrm{NiCrMo} 2$ çeliği $700^{\circ} \mathrm{C}$ sicaklık ve 4, 8, 12 ve 16 saat sürelerde borlama işlemine tabi tutulmuştur. Borlama ajanı olarak yerli borlama ajanı olan Baybora-1 kullanılmıştır. Numunelerin metal-borür tabakası ve geçiş tabakasının morfolojisi SEM cihazı ile belirlenmiş̧ir. Borlanmış numunelerin yüzeyinde oluşan metal-borür tabakasının faz analizleri XRD cihazı ile yapılmıştır. Borlanmış ve borlanmamış çelik numunelerin korozyon deneyi ASTM G31-72 standardına göre sıcak sülfürik asit çözeltisinde yapılmıştır. Numunelerin korozyon dayanımı ağırlık kaybı yöntemi ile belirlenmiştir. Borlanmış numunelerin korozyon dayanımı $323 \mathrm{~mm} / \mathrm{y} 1 \mathrm{l}$ iken borlanmamış numunenin $491 \mathrm{~mm} / \mathrm{yll}$ olduğu belirlenmiştir.

\section{Anahtar Kelimeler}

"Borlama, Seramik metal-borür tabaka, korozyon, 21NiCrMo2 çelik"

\begin{abstract}
Boriding is the process of coating the metal surface with a ceramic layer. As a result of the boronizing process, the entire surface of the metal is coated with a thin ceramic metal-boride layer. The aim of this study is to increase the corrosion resistance of $21 \mathrm{NiCrMo} 2$ steel by solid boriding method. In this study, $21 \mathrm{NiCrMo} 2$ steel was borided at $700 \mathrm{oC}$ and for $4,8,12$ and 16 hours. Baybora-1, a domestic boronizing agent, was used as the boronizing agent. The morphology of the metal-boride layer and the transition layer of the samples were determined by SEM device. The phase analyzes of the metal-boride layer formed on the surface of the boronized samples were made with the XRD device. Corrosion test of boronized and non boronized steel samples was carried out in hot sulfuric acid solution according to ASTM G31-72 standard. The corrosion resistance of the samples was determined by the weight loss method. While the corrosion resistance of boronized samples was $323 \mathrm{~mm} / \mathrm{year}$, it was determined that the non-boronized sample was $491 \mathrm{~mm} /$ year.
\end{abstract}

Key Words

"Boronizing, Ceramic metal-boride layer, corrosion, 21NiCrMo2 steel" 


\section{Giris}

Borlama, metallerin aşınmasını önlemek için metal yüzeyini seramik metal-borür tabakası ile kaplama işlemidir. Bor elementinin yüksek sıcaklıkta metal yüzeyine difüzyonu ile metal yüzeyinde çok sert bir metal-borür tabakası oluşur. Borlama işlemi ile metal yüzeyinde 5-300 $\mu \mathrm{m}$ kalınlığında seramik bir tabaka oluşur. Bu seramik tabaka, çeliklerde, demir-borür $\left(\mathrm{Fe}_{2} \mathrm{~B}\right)$ tabakası oluşur. Seramik metal-borür tabakası, testere dişi yapıda olduğu için metal-borür tabakasının alt tabakaya yapışması çok kuvvetlidir. Borlama işleminde, katı, sıvı ve gaz borlama gibi yöntemler bulunmaktadır. Katı borlama yöntemi, sıkı kapatılmış paslanmaz çelik kutularda yapılmaktadır. Borlama ajanı kapalı kutuya konulur ve iş parçası bu borlama ajanı içerisinde bekletilir. Borlama sıcaklığ $700-1100^{\circ} \mathrm{C}$ arasında değişebilmektedir. Borlama süresi 1 - 20 saat arasında yapılmaktadır. Çeliklerin borlanması sonucu çelik yüzeyinde demir-borür tabakası oluşur. Demir borürler termal ve elektrik iletkenliği gibi özelliklerine ek olarak yüksek sertlik gibi tipik seramik özellikleri de gösteren bileşiklerdir. Tane sınırları, dislokasyonlar, atom boşlukları gibi mikro hatalar ile yüzey pürüzlülükleri ve çizikler gibi yüzeyin daha reaktif olduğu yerler borür tabakası oluşumunun başlangıç noktalarıdır. Bu noktalarda metal-borür çekirdekleri oluşur ve büyür (Matuschka, 1980; Fichtl, 1981; Xu vd, 2000; Bayça vd., 2004). Akbayir v.d. (2005) AISI 1030 çeliğini, 900, 950, 1000, 1050 ${ }^{\circ} \mathrm{C}$ sıcaklıklarda 6 saat Ekabor-2 tozu ile borlama yapmışlardır. AISI 1030 çeliğinin metal-borür tabaka kalınlıkları sırası ile 178, 208,266 ve $341 \mu \mathrm{m}$ olarak ölçmüşlerdir. Borlama sıcaklığının artması ile metal-borür tabaka kalınlığı artmıştır. Kayali v.d. (2012) AISI 52100 çeliğini, 850, 900, $950^{\circ} \mathrm{C}$ sıcaklıklarda 4 saat Ekabor-2 tozu ile borlama yapmışlardır. AISI 52100 çeliğini borlama sonucunda 30 $187 \mu \mathrm{m}$ arasında metal-borür tabaka kalınlığı ölçmüşlerdir. Borlama sıcaklığının artması ile metal-borür tabaka kalınlığı artmıştır. Kayali v.d. (2012) AISI $440 \mathrm{C}$ çeliğini, $850,900,950^{\circ} \mathrm{C}$ sıcaklıklarda 4 saat Ekabor-2 tozu ile borlama yapmışlardır. AISI 440C çeliğini borlama sonucunda 6 - $58 \mu \mathrm{m}$ arasında metal-borür tabaka kalınlığı ölçmüşlerdir. Borlama sıcaklığının artması ile metal borür tabaka kalınlığı artmıştır. Genel v.d. (2006) AISI H13 çeliğini, $900^{\circ} \mathrm{C}$ sıcaklıklarda 5 saat Ekabor-1 tozu ile borlama yapmışlardır. AISI H13 çeliğinin metal-borür tabaka kalınlığını $30 \mu \mathrm{m}$ olarak ölçmüşlerdir. Uslu v.d. (2007) AISI 1040 çeliğini, $950{ }^{\circ} \mathrm{C}$ sıcaklıklarda 8 saat Ekabor-3 tozu ile borlama yapmışlardır. Metal-borür tabaka kalınlığını $190 \mu$ m olarak ölçmüşlerdir. Calik v.d. (2009) AISI 8620 çeliğini Ekabor-II borlama ajanı kullanarak katı yöntem ile $1210 \mathrm{~K}$ sıcaklıkta ve 4 saat süreyle borlamışlardır. Numunenin sertliği 395 HV iken borlama sonucu 1610 HV değerine yükseldiğini belirtmişlerdir. Testere dişi morfolojiye sahip bir metal borür tabakasının oluştuğunu rapor etmişlerdir. Oluşan metal borür tabakasının 55-65 $\mu \mathrm{m}$ kalınlıkta olduğunu ifade etmişlerdir. An v.d. (2012) AISI 8620 çeliğini $20 \mathrm{~mm}$ çap ve $10 \mathrm{~mm}$ uzunlukta $860^{\circ} \mathrm{C}$ sıcaklıkta 5 saat süre ile katı borlama yöntemi borlamışlardır. Borür tabakasında FeB ve $\mathrm{Fe}_{2} \mathrm{~B}$ fazları gözlemişlerdir. Borür tabaka kalınlığını $65 \mu \mathrm{m}$ ölçmüşlerdir. Testere dişi morfolojiye sahip bir borür tabakası elde etmişlerdir. Borlanmış ve borlanmamış çeliklerin korozyon testi $\mathrm{H}_{2} \mathrm{~S}$ doymuş petrol sahası suyu ortamında yapmışlardır. Borlanmış AISI 8620 çeliğinin borlanmamış numuneye göre korozyon dayanımının mükemmel olduğunu beyan etmişlerdir. Gunes vd. (2013) AISI 8620 çeliğini sıvı borlama yöntemi ile borlamışlardır. $750{ }^{\circ} \mathrm{C}$ sıcaklıkta 5 saat borlama sonucunda $91 \mu \mathrm{m}$ kalınlığında ve 1598$1976 \mathrm{HV}$ sertliğinde ve $\mathrm{FeB}$ ve $\mathrm{Fe}_{2} \mathrm{~B}$ fazlarından oluşan bir borür tabakası elde etmişlerdir. Borlama işleminin aktivasyon enerjisini $99,773 \mathrm{~kJ} / \mathrm{mol}$ olarak hesaplamışlardır. Gunes vd (2011) AISI 8620 çeliğini $800{ }^{\circ} \mathrm{C}$ sıcaklıkta 5 saat borlama süresinde $35 \mu \mathrm{m}$ borür tabaka kalınlığı elde etmişlerdir. Borür tabaka kalınlığı borlama sıcaklığı ve borlama süresinin artması ile arttığını rapor etmişlerdir. Borür tabakasında $\mathrm{FeB}$ ve $\mathrm{Fe}_{2} \mathrm{~B}$ fazlarını gözlemlemişlerdir. An v.d. (2012) AISI 8620 çeliğini $800{ }^{\circ} \mathrm{C}$ sıcaklıkta 5 saat süre ile borlamışlardır. Numunenin sertliği 340 HV iken katı borlama sonucunda 1200-1340 HV sertliğine yükseldiğini ifade etmişlerdir. Borlanmış çelik, hidrojen sülfür ile doymuş petrol sahası suyunda korozyona maruz bırakıldığı zaman borlanmamış çeliğe göre daha yüksek korozyon direncine sahip olduğunu belirtmişlerdir. Krelling ve ark. (2017), AISI 1020 çeliğini $1000{ }^{\circ} \mathrm{C}^{\prime}$ de 4 saat katı borlama yöntemi ile borlama işlemi sonucunda çelik yüzeyinin metal-borür tabakası ile kaplandığını rapor etmişlerdir. Kaplama yapısının sertliği ve aşınma direnci incelenmiştir. XRD analizi tek fazlı bir $\mathrm{Fe}_{2} \mathrm{~B}$ yapısının varlığını göstermiştir. Elde edilen demir-borür yapı $177 \mu \mathrm{m}$ kalınlığa ve 2100 HV0.01 sertliğe sahiptir. Yerli borlama ajanı Baybora-1 kullanılarak yapılan borlama çalışmalarından bazıları aşağıda verilmiştir. Bican v.d. (2020) AISI 5140 çeliğini yerli borlama ajanı (Baybora-1) ile borlamışlar ve $950{ }^{\circ} \mathrm{C}$ sıcaklıkta 4 saat borlama sonucunda $90 \mu \mathrm{m}$ metal-borür tabaka kalınlığına ulaşmışlardır. Bayça v.d. (2020) AISI 4140 çeliğini yerli borlama ajanı (Baybora-1) ile borlamışlardır. Borlanmamış çeliğin korozyon hızı $0,01 \mathrm{~mm} / \mathrm{y} 1 \mathrm{l}$ iken $950^{\circ} \mathrm{C}$ sıcaklıkta 4 ve 6 saat borlanmış çeliğin korozyon hızı 0,007 mm/yıl değerine düşmüştür. Ocak-Araz vd (2021) 304L çeliği yerli borlama ajanı (Baybora-1) ile borlamışlardır. $950^{\circ} \mathrm{C}$ sıcaklıkta 2 saat borlama sonucunda $20 \mu \mathrm{m}$ iken 8 saat borlama sonucunda $51 \mu \mathrm{m}$ seramik metal-borür tabakası elde edilmiştir. Nükleer uygulamalar için radyasyon koruyucu malzeme olarak borlanmış çelik içeren kompozit malzemeler, mikron boyutunda bor kullanılan kompozit malzemelerden daha uygundur. Bican vd. (2021) 304L çeliğini yerli borlama ajanı (Baybora-1) ile borlamışlardır. Borlanmış ve borlanmamış çelikler oldukça farklı erozyon dirençlerine ve aşındırıcı parçacıkların çarpma açısına bağımlıdır. Küçük çarpma açılarında, borlanmış çelik yüksek bir erozyon direncine sahiptir, ancak büyük çarpma açılarında erozyon özellikleri, borlanmamış çeliğe göre daha düşüktür. Borlama çeliğin yüzeyini kırılgan hale getirdiğinden, aşındırıcı parçacıkların çarpma açısının büyümesi, sünek bir malzeme için tipik olandan kırılgan bir malzeme için tipik olan erozyon davranışını değiştirir.

Borlama işlemleri ile çeliklerin yüzeyinde 5-300 $\mu \mathrm{m}$ kalınlığında seramik metal-borür tabakası oluşmaktadır. Düşük sıcaklıklarda (750 $\left.{ }^{\circ} \mathrm{C}\right)$ ince seramik metal-borür tabakası oluşur iken yüksek sıcaklıklarda $\left(1050{ }^{\circ} \mathrm{C}\right)$ kalın seramik metal-borür tabakası oluşmaktadır. Kısa borlama süresinde (1h) ve sabit sıcaklıklarda ince seramik metal-borür tabakası oluşur iken uzun borlama süresinde $(8 \mathrm{~h})$ ve sabit sıcaklıklarda kalın seramik metal-borür tabakası oluşmaktadır. Literatürde, genel olarak ticari ve ithal Ekabor markası ile satılan katı borlama ajanı kullanılmıştır. Ekabor markasının birden fazla borlama ajanı bulunmaktadır. Bunlar, Ekabor-1, Ekabor-2 ve Ekabor HM gibi adlarla piyasada satılmaktadır. Borlama işlemleri ile çeliklerin korozyon direncinin arttığı literatürde rapor edilmiştir.

$\mathrm{Bu}$ çalışmanın amac1, 21NiCrMo2 çeliğinin korozyon dayanımına borlama işleminin etkilerini araştırmaktır. Borlama işleminde, Baybora-1yerli borlama ajanı kullanılmıştır. Borlanmamış ve borlanmış numunelerin SEM analizleri, kimyasal analizleri, XRD 
analizleri yapılmıştır. Çeliğin korozyon hızını belirlemek için ASTM G31-72 standardında belirtilen ağırlık kaybı yöntemi kullanılarak korozyon testi yapılmıştır. Çelik numuneler, $56^{\circ} \mathrm{C}$ sıcaklıktaki, \% 10 sülfürik asit ve\% 90 saf su içeren bir çözeltiye daldırılmış ve ağırlıkları ölçülmüştür.

\section{Malzeme ve yöntem}

\subsection{Malzeme}

Borlama yöntemi ile seramik metal-borür kaplama işleminde altlık malzeme olarak $21 \mathrm{NiCrMo} 2$ çelik seçilmiştir. $21 \mathrm{NiCrMo} 2$ çelik çubuk torna ile $15 \mathrm{~mm}$ çapında ve $20 \mathrm{~mm}$ uzunluğunda silindirik numuneler hazırlanmıştır.

\subsection{Borlama İşlemi}

Bu çalışmada yeni bir borlama ajanı olan ve Patenti Salih Uğur BAYÇA tarafından alınan yerli borlama ajanı (Bayça, 2021) kullanılmıştır. Bu borlama ajanı Baybora-1 markası ile tanımlanmışıı. Katı borlama, 304L paslanmaz çelik potada gerçekleştirilmiştir. Çelik pota elektrikli kamara tip fırında isıtılmıştır.

Tipik bir borlama deneyinde, toz borlama ajanı potanın hacimce yarısına kadar doldurulmuştur. Çelik numuneler bu toz borlama ajanı içine gömülmüştür. Potanın geri kalan hacmine deoksidan malzeme doldurulmuştur. Pota kapağından hava sızdırmayı önlemek için vidalı kapak sıkıca kapatılmış ve fırına yerleştirilmiş ve firında belirli sıcaklık ve sürede 1sıtılmıştır. Bu sürenin sonunda, pota firında soğumaya bırakılmıştır.

\subsection{Numune Hazırlama}

Borlanmış ve borlanmamış silindirik numuneler kesme cihazı ile yaklaşık $2 \mathrm{~mm}$ kesilmiştir. Kesilmiş numune yüzeyleri sırasıyla 800 ve 1200 gritlik zımpara kağıtları ile zımparalanmıştır. Parlatma işlemi $6 \mu$ elmas solüsyonlar ile keçe kullanılarak yapılmıştır. Mikro yapının incelenmesi için gerekli olan dağlayıcı olarak \%4 nital çözeltisinde numuneler sırasıyla 5 saniye sürede bekletilip suyla temizlenmiştir. Temizlenen numunelerin üzerine etil alkol damlatılarak ve kurutulmuştur.

\subsection{Korozyon Testi}

21NiCrMo2 çeliğinin korozyona direncini belirlemek için ağırlık kaybı yöntemi kullanılmıştır. ASTM G31-72 standardında belirtilen ağırlık kaybı yöntemi kullanılarak korozyon testi yapılmıştır (ASTM, 2004). Ağırlık kaybı ölçümleri, 200 mL test çözeltileri içeren $250 \mathrm{~mL}$ 'lik bir beherde yapılmıştır. Çelik numuneler zımpara kağıdı ile temizlenmiş ve $0.1 \mathrm{mg}$ hassasiyetteki bir terazide tartılmıştır. Korozyon deney düzeneği Şekil 1 de verilmiştir.

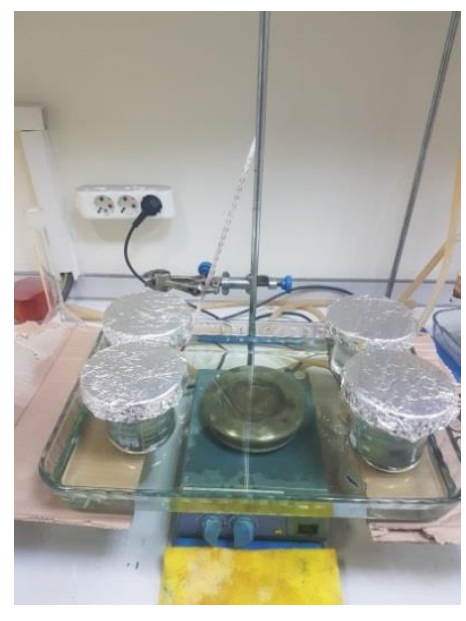

Şekil 1. Korozyon test düzeneği

Korozyon deneyinde, 1sıtıcılı manyetik karıştıııcı üzerinde bulunan cam kap üzerine beherler yerleştirilmiştir. Cam kap içine su konularak manyetik karıştırıcı ile 1sıtılmıştır. Çelik numuneler, $56^{\circ} \mathrm{C}$ sıcaklıktaki, $\% 10$ sülfürik asit ve $\% 90$ saf su içeren bir çözeltiye daldırılmış ve 1,10 ve 24 saat boyunca bekletilmiştir. Korozyon çözeltisinden çıkan çelik numuneler saf su ile yıkanmış ve kurutulmuştur. Kuru numuneler terazide tartılmıştır. Korozyon hızı (CR), aşağıda verilen denklem ile hesaplanmıştır.

$$
C R=\frac{W}{d A t}
$$

Burada $C R, \mathrm{~cm} / \mathrm{saat}$ cinsinden korozyon hızı, $W$ numunenin g cinsinden ağırlık kaybıdır, $A$ numunenin $\mathrm{cm}^{2}$ cinsinden yüzey alanıdır, $d$ numunenin $\mathrm{g} / \mathrm{cm}^{3}$ cinsinden yoğunluğu ve $t$ numunenin çözeltide bekletilme süresidir. 


\subsection{Karakterizasyon}

Metal-borür fazlar bir Rigaku Ultima IV marka X-ışını difraktometresi kullanılarak belirlenmiştir. Tarama hızı 2 derece/dak, tarama ekseni 2 teta/teta, tarama modu sürekli ve örnekleme genişliği 0,200 derece idi. Tartımlar Sartorius marka terazi ile yapılmıştır. SEM analizi FEI Quanta-400F cihazı ile yapılmıştır. Çeliğin kimyasal analizi Metek Spectromaxx spektrometre cihazı ile yapılmıştır.

\section{Bulgular ve Tartışma}

\subsection{Mikroyapı}

Metal-borürler kovalent bağlı bileşikler olduğu için metal-borürler oksit olmayan seramik grubundadır. Bir metal borlama işlemine tabi tutulduğu zaman metal yüzeyinde mikrometre kalınlığında metal-borür tabakası ile kaplanmaktadır. Bu yüzden, borlama işlemi metal yüzeyini seramik bir tabaka ile kaplama olarak da adlandırabilir.

Bu çalışmada, çelik silindir numuneler 1-2 mm kesilerek zımparalanmış, dağlanmış ve parlatılmıştır. Çelik numunenin parlatılmış üst yüzeyini görüntülemek için SEM analizi yapılmıştır. $21 \mathrm{NiCrMo} 2$ çeliği $700^{\circ} \mathrm{C}$ sıcaklıkta ve 4 saat süre ile borlanmış numunelerin SEM analizi Şekil 2a da verilmiştir. Çelik numunenin borlanması sonucu yüzeyde testere dişi bir morfolojiye sahip olduğu görülmüştür. $21 \mathrm{NiCrMo} 2$ çeliği $700^{\circ} \mathrm{C}$ sıcaklıkta ve 4 saat süre ile borlanmış yüzeyinde $7,70 \mu \mathrm{m}$ kalınlığında metal-borür tabakası elde edilmiştir. $700^{\circ} \mathrm{C}$ sıcaklık ve 8 saat süre ile borlanmış numunelerin yüzeyinde $10,20 \mu \mathrm{m}$ kalınlığında metal-borür tabakası ölçülmüştür (Şekil 2b).

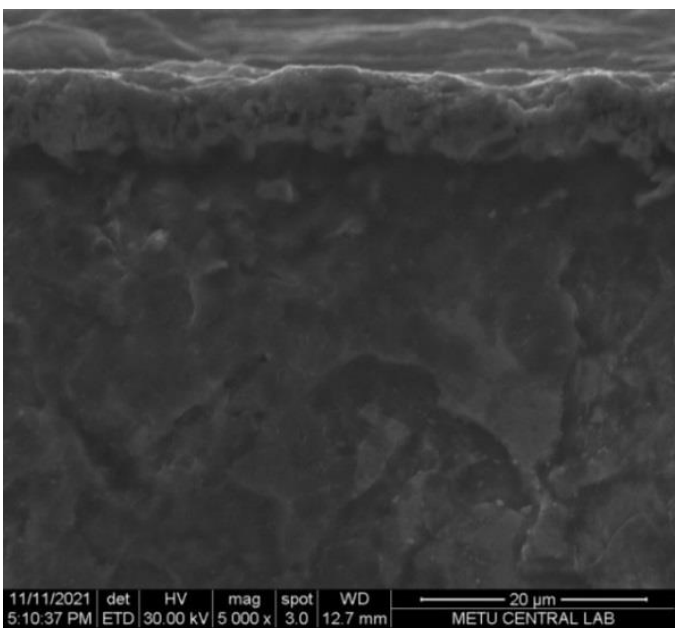

a)

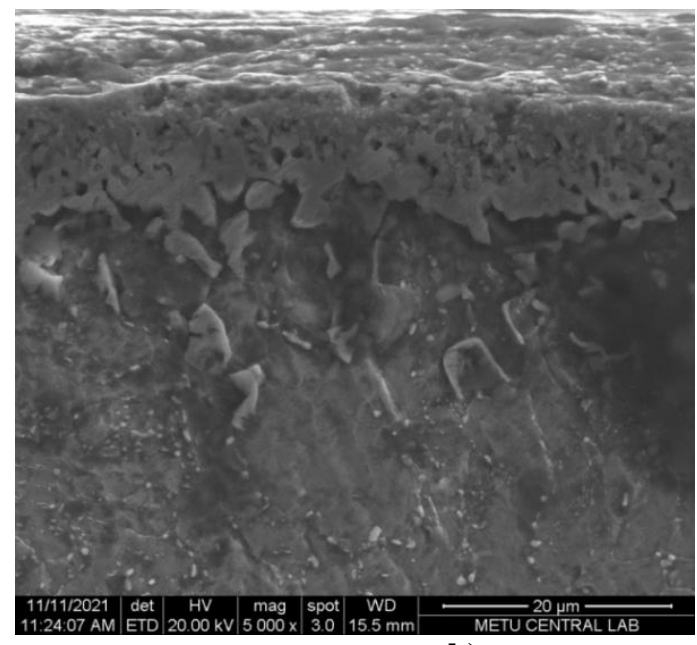

b)

Şekil 2. a) $700{ }^{\circ} \mathrm{C}$ sıcaklıkta 4 saat borlanmış numune SEM analizi, b) $700{ }^{\circ} \mathrm{C}$ sıcaklıkta 8 saat borlanmış numunenin SEM analizi

$21 \mathrm{NiCrMo} 2$ çeliği $700^{\circ} \mathrm{C}$ sıcaklıkta ve 12 saat süre ile borlanmış ve çelik yüzeyinde $12,25 \mu \mathrm{m}$ kalınlığında metal-borür tabakası gözlenmiştir (Şekil 3a). Bu çelik numune $700^{\circ} \mathrm{C}$ sicaklıkta ve 16 saat süre ile borlanmış ve çelik numune yüzeyinde $15,23 \mu \mathrm{m}$ kalınlığında metal-borür tabakası oluşmuştur (Şekil 3b). Bu metal-borür tabakası testere dişi bir morfolojide olduğu görülmektedir.

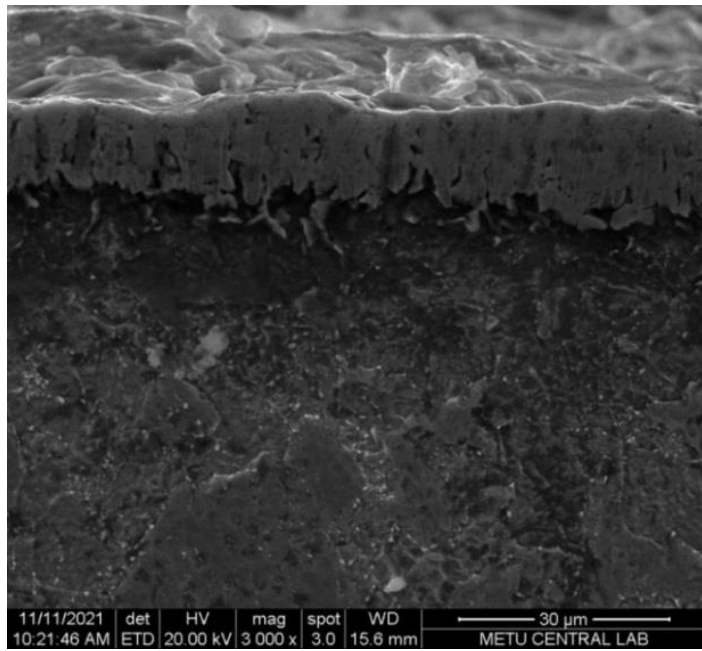

a)

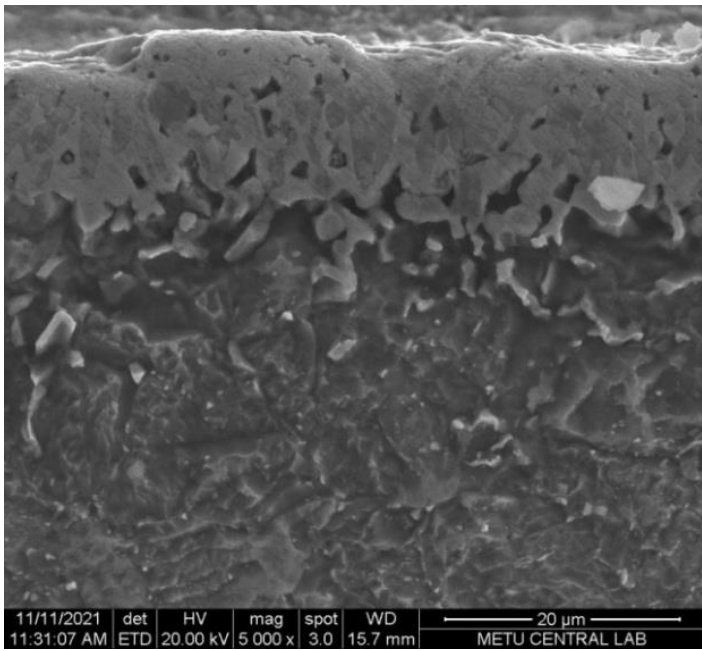

b)

Şekil 3. a) $700^{\circ} \mathrm{C}$ sıcaklıkta 12 saat borlanmış numune SEM analizi, b) $700^{\circ} \mathrm{C}$ sıcaklıkta 16 saat borlanmış numunenin SEM analizi 
SEM analizinde $700^{\circ} \mathrm{C}$ sıcaklıkta borlanmış numunelerin borlama süresinin artması sonucu seramik metal-borür tabaka kalınlığı artmıştır. Seramik metal-borür tabaka kalınlığının artması beklenen bir durumdur. Borlama sıcaklı̆̆ı sabit iken borlama süresinin artması ile metal-borür tabakasının kalınlığı artmıştır. Bu artış, borlama işlem süresinin artmasıyla altlık metale bor difüzyonunun devam etmesinden kaynaklanmış olabilir.

\subsection{Faz Analiz Sonuçları}

$\mathrm{Bu}$ çalışmada kullanılan çeliğin kimyasal analizi spektrometre cihazı ile yapılmıştır. Tablo 1 de borlanmamış $21 \mathrm{NiCrMo} 2$ çeliğinin kimyasal bileşimi verilmiştir.

Tablo 1. Borlanmamış 21NiCrMo2 çeliğinin kimyasal bileşimi

\begin{tabular}{ll}
\hline Element & $\%$ \\
\hline $\mathrm{C}$ & 0,1920 \\
$\mathrm{Mn}$ & 0,8370 \\
$\mathrm{Ni}$ & 0,5710 \\
$\mathrm{Cr}$ & 0,5200 \\
$\mathrm{Si}$ & 0,2700 \\
$\mathrm{Mo}$ & 0,2340 \\
$\mathrm{P}$ & 0,0134 \\
$\mathrm{~S}$ & 0,0134 \\
$\mathrm{Co}$ & 0,0123 \\
$\mathrm{Al}$ & 0,0423 \\
$\mathrm{Fe}$ & 97,200 \\
\hline
\end{tabular}

Çeliğin kimyasal analizinde ana element demir iken minör elementler olarak mangan, nikel, krom, silisyum, molibden ve karbon içerdiği belirlenmiştir. $21 \mathrm{NiCrMo} 220$ çeliğinin düşük alaşımlı çelik grubunda olduğu Tablo 1 de kimyasal bileşimden anlaşılmaktadır.

Borlama işlemi sonucu çelik yüzeyi metal-borür tabakası ile kaplanmaktadır. Bu metal-borür tabakası çelik numunesinin kimyasal içeriğine göre bor ile metalin yaptığı bileşiklerden oluşmaktadır. Bor elementi dışardan difüzyon ile çelik yüzeyinden içeri doğru difüze olmaktadır. Çelik numune bileşiminde demir olduğu için bor ile demir reaksiyonu sonucu Fe-B bileşikleri oluşmaktadır. Çelik numune bileşiminde nikel olduğu zaman Ni-B bileşikleri oluşmaktadır.

$700{ }^{\circ} \mathrm{C}$ sıcaklıkta 4 saat borlanmış numunenin XRD analizi Şekil 4 de verilmiştir. Çelik numunesinin $700{ }^{\circ} \mathrm{C}$ sıcaklıkta ve 4 saat borlanması ile elde edilen numunenin XRD sonuçlarında majör faz $\mathrm{Fe}_{2} \mathrm{~B}$ olduğu gözlenmiştir. $\mathrm{Bu}$ numunede FeB fazı gözlenmemiştir. Minör fazlar olarak $\mathrm{Fe}_{2} \mathrm{~B}$ ve $\mathrm{NiB}$ fazı da gözlenmiştir. Ki bu çelik içerisinde bulunan nikelin varlı̆̆ından kaynaklanabilir.

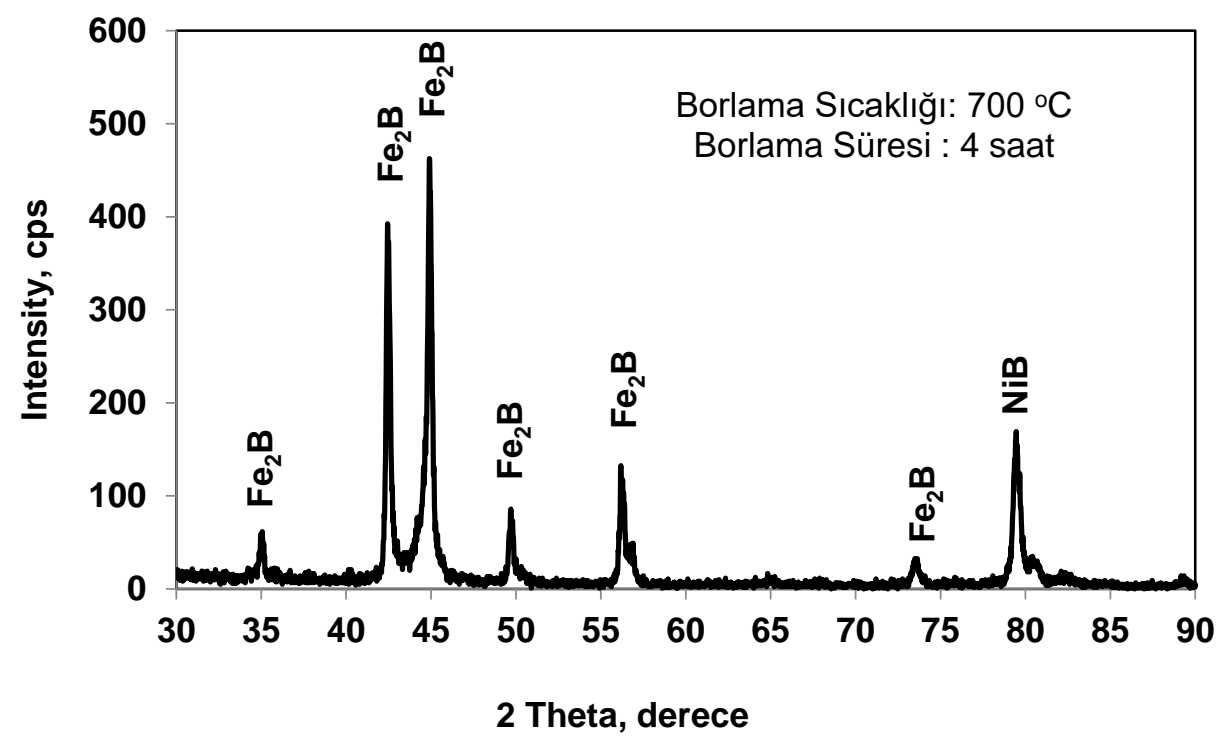

Şekil 4. $700{ }^{\circ} \mathrm{C}$ sıcaklıkta 4 saat borlanmış numune XRD analizi 
$700{ }^{\circ} \mathrm{C}$ sıcaklıkta 8 saat borlanmış numunenin XRD analizi Şekil 5 de verilmiştir. $21 \mathrm{NiCrMo} 220$ çelik numunesinin $700^{\circ} \mathrm{C}$ de 8 saat borlanması sonucu $\mathrm{Fe}_{2} \mathrm{~B}$ major faz olarak belirlenmiştir. Minor fazlar olarak $\mathrm{Fe}_{2} \mathrm{~B}$ ve $\mathrm{NiB}$ fazları gözlenmesine rağmen $\mathrm{FeB}$ fazı gözlenmemiştir.

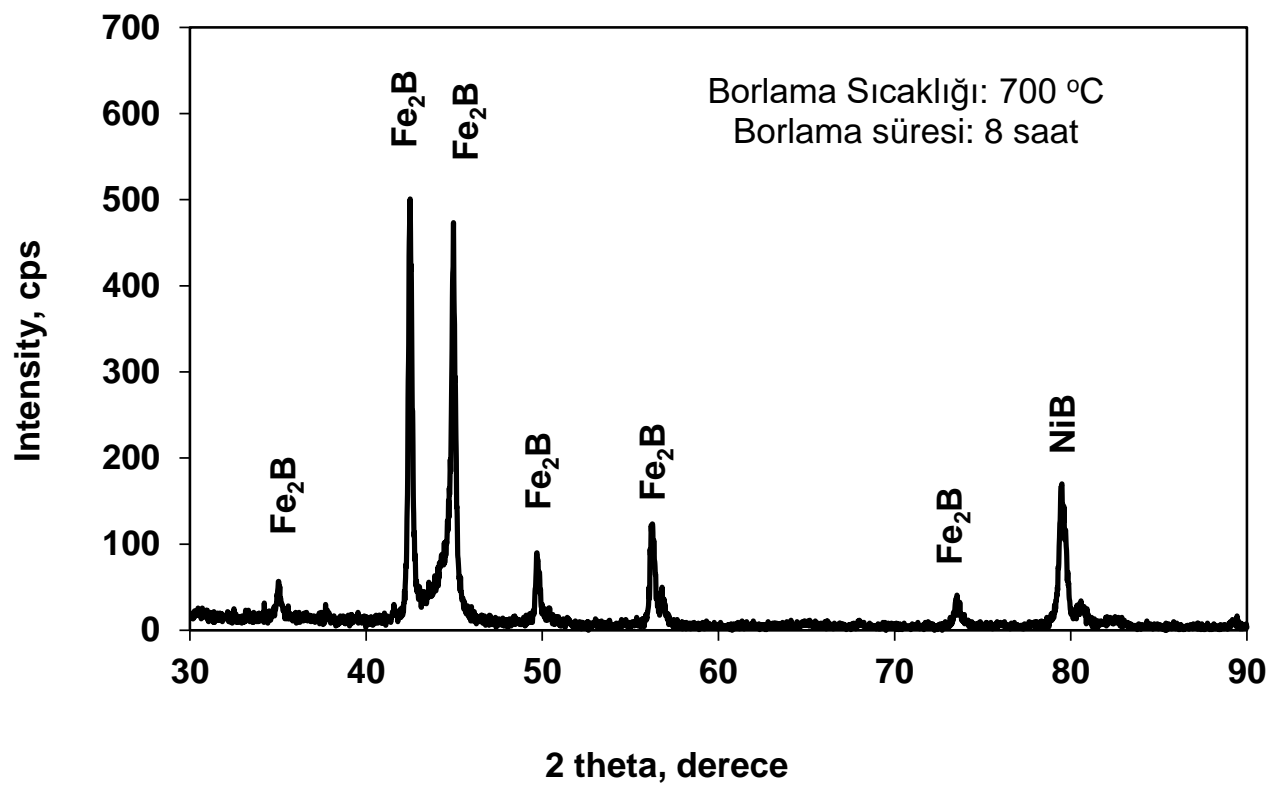

Şekil 5. $700^{\circ} \mathrm{C}$ sıcaklıkta 8 saat borlanmış numune XRD analizi

$700^{\circ} \mathrm{C}$ sıcaklıkta 12 saat borlanmış numunenin XRD analizi Şekil 6 da verilmiştir. Çelik numunenin $700^{\circ} \mathrm{C}$ sıcaklıkta ve 12 saat borlanması sonucu majör olarak $\mathrm{Fe}_{2} \mathrm{~B}$ fazları gözlenmiştir. Minör fazlar olarak $\mathrm{FeB}, \mathrm{Fe}_{2} \mathrm{~B}$ ve $\mathrm{NiB}$ fazları gözlenmiştir.

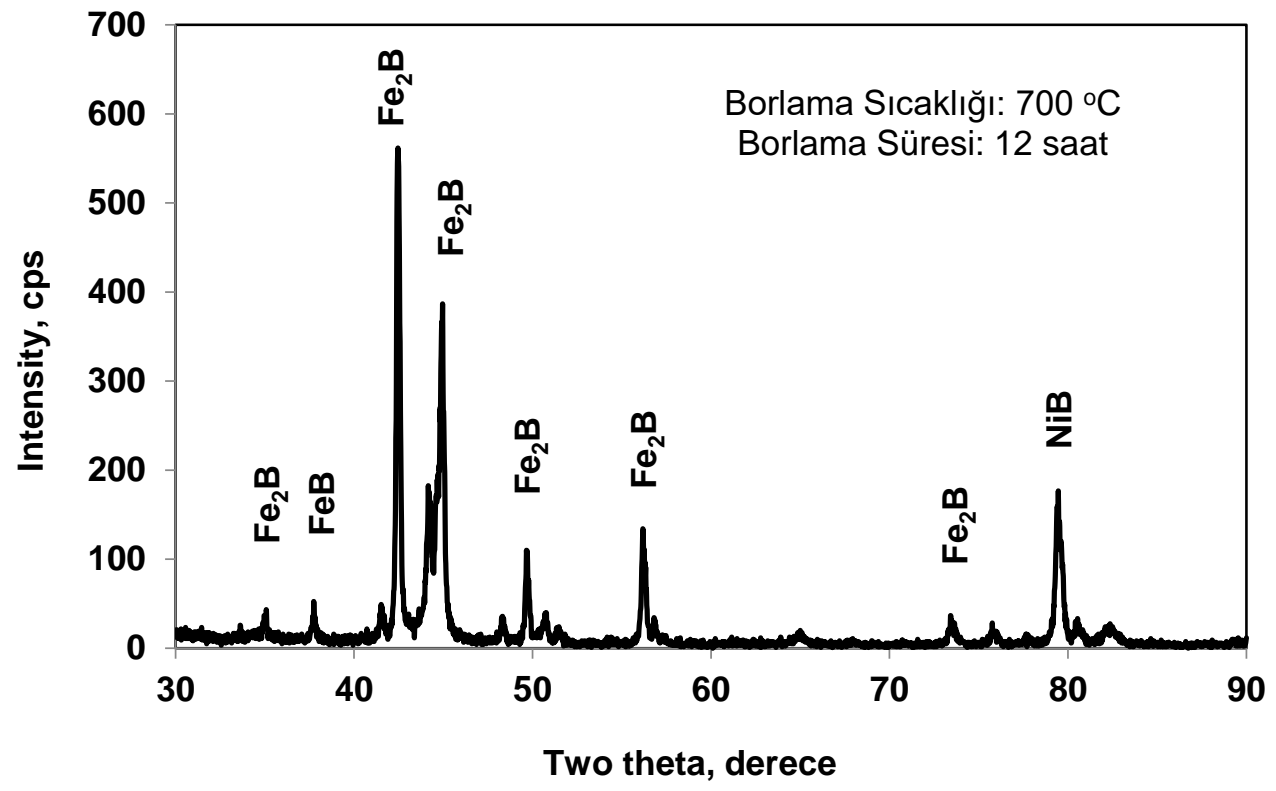

Şekil 6. $700^{\circ} \mathrm{C}$ sıcaklıkta 12 saat borlanmış numune XRD analizi

Şekil 6 da daha önce görülmeyen FeB fazı görülmüştür. Bu FeB fazı yüzeye tutunma açısından zayıf bir faz olduğu için genel olarak istenmeyen bir fazdır.

$700{ }^{\circ} \mathrm{C}$ sıcaklıkta ve 16 saat borlanmış numunenin XRD analizi Şekil 7 de verilmiştir. $21 \mathrm{NiCrMo} 2$ çeliğinin $700{ }^{\circ} \mathrm{C}$ sıcaklıkta ve 16 saat borlanması ile majör fazlar olarak $\mathrm{Fe}_{2} \mathrm{~B}, \mathrm{Ni}_{3} \mathrm{~B}, \mathrm{Mo}_{2} \mathrm{~B}$ ve $\mathrm{CrB}$ fazları oluşmuştur. Minör fazlar olarak $\mathrm{FeB}, \mathrm{Fe}_{2} \mathrm{~B}, \mathrm{NiB}$ fazları oluştuğu gözlenmiştir. 


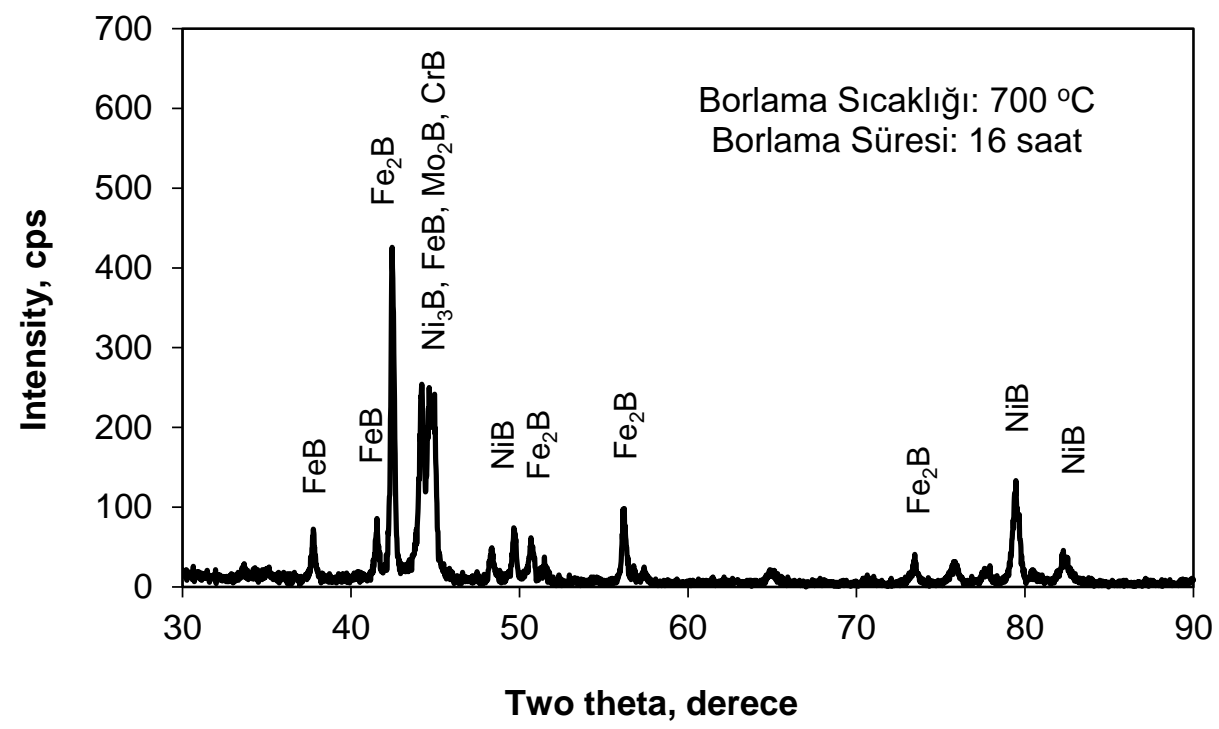

Şekil 7. $700{ }^{\circ} \mathrm{C}$ sıcaklıkta 16 saat borlanmış numune XRD analizi

$700{ }^{\circ} \mathrm{C}$ sabit sıcaklıkta borlama işlemine tabi tutulan çeliğin XRD analizlerinde borlama süresi 4-12 saat arasında olduğu zaman majör faz olarak sadece $\mathrm{Fe}_{2} \mathrm{~B}$ fazı gözlenmiştir. Borlama süresi 16 saat olduğu zaman çelik yüzeyinde $\mathrm{Fe}_{2} \mathrm{~B}, \mathrm{FeB}, \mathrm{Ni}_{3} \mathrm{~B}, \mathrm{Mo}_{2} \mathrm{~B}$ ve $\mathrm{CrB}$ fazları oluşmuştur. Bu fazlar içerisinde $\mathrm{Fe}_{2} \mathrm{~B}$ fazının alt tabaka çeliğe yapışması çok kuvvetlidir. Ancak FeB fazının alt tabakaya yapışması kuvvetli olmadığı için bu FeB tabakası kolayca uzaklaşmaktadır. Bu nedenle, sürtünmeli çalışan makinelerde bu FeB tabakası çok kısa sürede aşınmaktadır. $21 \mathrm{NiCrMo} 2$ çeliğinin $700^{\circ} \mathrm{C}$ sabit sıcaklıkta, borlama süresi 12 saat den az olmalıdır. Bu süreye ulaşıldığı zaman çelik yüzeyinde FeB fazı da gözlenmektedir.

\subsection{Korozyon Hizı}

21NiCrMo2 çeliği $700{ }^{\circ} \mathrm{C}$ sıcaklıkta 4, 8, 12 ve 16 saat sürelerde borlanmıştır. Borlanmamış ve borlanmış çelik numuneler ASTM G31-72 standardında korozyon testine tabi tutulmuştur.

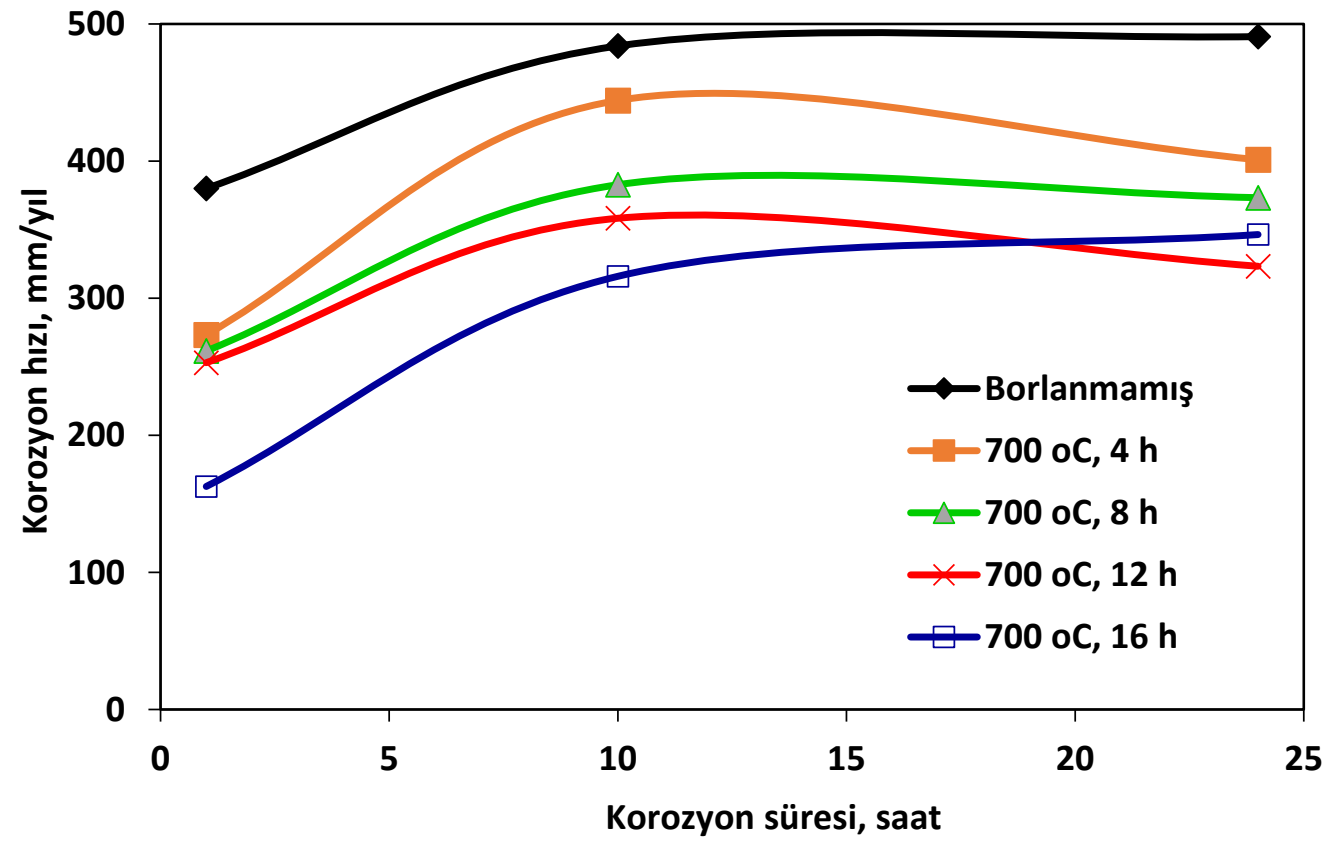

Şekil 8. $700{ }^{\circ} \mathrm{C}$ sıcaklıkta borlanmış numunelerin korozyon hızı

Borlanmamış ve borlanmış çelik numunelerin korozyon hızı mm/yıl olarak Şekil 8 de verilmiştir. Borlanmamış numunenin 24 saat korozyon süresi için korozyon hızı $491 \mathrm{~mm} / \mathrm{y} 1 \mathrm{l}$ olarak bulunmuştur. Çelik numune $700{ }^{\circ} \mathrm{C}$ sabit sıcaklıkta 4 saat borlanmış ve bunu takiben yapılan 24 saat korozyon için korozyon hızı $401 \mathrm{~mm} / \mathrm{y} 1 \mathrm{l}$ olduğu belirlenmiştir. Çelik numune $700{ }^{\circ} \mathrm{C}$ sabit sıcaklıkta 8 saat borlanmış ve 24 saat korozyon süresi için korozyon hızı $373 \mathrm{~mm} / \mathrm{y} ı l$ olarak bulunmuştur. $700{ }^{\circ} \mathrm{C}$ sabit sıcaklıkta 12 saat borlanmış 


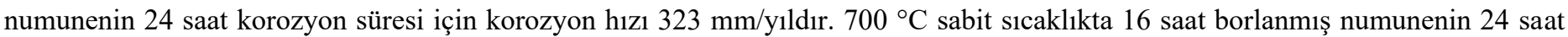
korozyon süresi için korozyon hızı $346 \mathrm{~mm} / \mathrm{y} ı 1$ olarak belirlenmiştir. Korozyon süresinin artması ile korozyon hızı artmıştır. Borlanmamış numunenin korozyon hızı borlanmış numunelerin korozyon hızından daha yüksektir. En düşük korozyon hızı $700{ }^{\circ} \mathrm{C}$ sabit sıcaklıkta 12 saat borlama yapılmış numunede gözlenmiştir.

\section{Sonuçlar}

Bu çalışmada, 21 NiCrMo2 çeliği yerli borlama ajanı (Baybora-1) kullanılarak $700^{\circ} \mathrm{C}$ sıcaklıkta ve farklı sürelerde borlanmıştır.

Borlama sıcaklığı sabit iken borlama süresinin artması ile seramik metal-borür tabakasının kalınlı̆̆ı artmıştır. Bu artış, borlama işlem süresinin artmasıyla altlık metale bor difüzyonunun devam etmesinden kaynaklanmış olabilir.

Sonuçlar göstermiştir ki $21 \mathrm{NiCrMo} 2$ çeliğinin $700{ }^{\circ} \mathrm{C}$ sabit sıcaklıkta, borlama süresi 12 saat olduğu zaman çelik yüzeyinde FeB fazı oluşmaya başlamıştır. Borlama süresi 16 saat iken FeB fazında artış olmuştur.

Borlanmış ve borlanmamış çelik numunelerin korozyon deneyi ASTM G31-72 standardına göre sıcak $\left(56^{\circ} \mathrm{C}\right)$ sülfirik asit çözeltisinde yapılmıştır. Korozyon süresinin artması ile korozyon hızı artmışıı. Borlanmamış numunenin korozyon hızı borlanmış numunelerin korozyon hızından daha yüksektir. En düşük korozyon hızı $700^{\circ} \mathrm{C}$ sabit sıcaklıkta 12 saat borlama yapılan numunede gözlenmiştir.

\section{Referanslar}

Akbayır, O. (2005). The effect of treatment parameters on surface and wear properties of boronized AISI 1030 steel by pack method, Thesis, Osmangazi University.

An, J., Su, Z. G., Gao, X. X., Yang, Y. L., \& Sun, S. J. (2012). Corrosion Characteristics of Boronized AISI 8620 Steel in Oil Field Water Containing $\mathrm{H}_{2} \mathrm{~S}$, Physicochemical problems on materials protection 48, 487 - 494.

An., J., Li., C., Wen, Z., Yang, Y.L., \& Sun, S.J. (2012). A Study of boronizing of steel AISI 8620 for sucker rod Metal Scence and Heat Treatment 53, $598-602$.

ASTM G31-72 (2004). Standard practice for laboratory immersion corrosion testing of metals, USA.

Bayca, S.U., \& Sahin, S. (2004). Boriding, Machinery and Engineer, TMMOB, Chamber of Mechanical Engineers, Ankara, 532, 51 59.

Bayça, S.U. (2021). Bir katı borlama ajanı, Patent no: TR2021/007143.

Bayça, S.U., Bican, O., Yamanel, B., Hekimoğlu A.P., \& Çalış, M. (2020). The Effect of Solid Boriding Time on the Structure, Hardness and Corrosion Properties of AISI 5140 Steel, Protection of metals and Physical Chemistry of Surfaces, 56, (3) 591-597.

Bican, O., Bayca, S.U., Ocak-Araz, S., Yamanel, B., \& Tanis, N.A. (2020). Effects of the boriding process and of quenching and tempering after boriding on the microstructure, hardness and wear of AISI 5140 steel, Surface Review and Letters, 27, (6) 1950157$1-9$.

Bican, O., Bayça, S.U., Kuleyin, H., \& Gümrük, R., (2021). Effect of boronizing operating stability of steel AISI 304L under erosion impact of hard particles, Metal Science and Heat Treatment, 63, (3-4) 156 - 162.

Calik A.,, Duzgun, A., Ekinci, A.E., Karakas, S., \& Ucar, N., (2009). Comparison of Hardness and Wear behaviour of Boronized and Carburized AISI 8620 Steels, Acta Physica Polonica A 116, 1029-1032.

Fichtl, W. (1981). Boronizing and its practical applications, Materials in engineering 2, 276 - 286.

Genel, K. (2006). Boriding kinetics of H13 steel, Vacuum 80, 451-457.

Gunes, I., Ulker, S., \& Taktak, S. (2011). Plasma paste boronizing of AISI 8620, 52100 and 440C steels, Materials design 32, $2980-$ 2986.

Gunes, I., Ulker, S., \& Taktak, S. (2013). Kinetics of Plasma Paste Boronized AISI 8620 Steel in Borax Paste Mixtures, Protection of Metals and Physical Chemistry of Surfaces, 49, 567-573.

Kayali, Y., Gunes, I., \& Ulu, S. (2012). Diffusion kinetics of borided AISI 52100 and AISI 440C steels. Vacuum 86, 1428 - 1434. 
Matuschka, A.G. (1980). Boronizing, Carl Hanser Verlag, München, Germany.

Ocak-Araz, S., Gumus, H., Bayca, S.U., \& Aydin, A. (2021). Investigation of gamma-ray attenuation coefficients for solid boronized 304L tainless steel, Applied Radiation and Isotopes, 170, 109605.

Uslu, I., Comert, H., Ipek, M., Celebi, F.G., Ozdemir, O., \& Bindal, C. (2007). A comparison of borides formed on AISI 1040 and AISI P20 steels, Materials and Design 28, 1819-1826.

Xu, C.H., Gao, W., \& Yang, Y.L. (2000). Superplastic Boronizing of a Low Alloy Steel- Microstructural Aspects, Journal of Materials Processing Technology, 108, 349-355. 